\title{
Excitation-contraction coupling and mechano-sensitivity in denervated skeletal muscles
}

\author{
Fabio Francini, Roberta Squecco
}

Department of Physiological Sciences, University of Florence, Italy

\begin{abstract}
Skeletal muscle atrophy can be defined as a wasting or decrease in muscle mass and muscle force generation owing lack of use, ageing, injury or disease. Thus, the etiology of atrophy can be different. Atrophy in denervated muscle is a consequence of two factors: 1) the complete lack of motoneuron activity inducing the deficiency of neurotransmitter release and 2) the muscles disuse. The balance of the muscular functions depends on extra- and intra-muscular signals. In the balance are involved the excitation-contraction coupling (ECC), local growth factors, $\mathrm{Ca}^{2+}$-dependent and independent intracellular signals, mechano-sensitivity and mechano-transduction that activate $\mathrm{Ca}^{2+}$-dependent signaling proteins and cytoskeletonnucleus pathways to the nucleus, that regulate the gene expression. Moreover, retrograde signal from intracellular compartments and cytoskeleton to the sarcolemma are additional factors that regulate the muscle function. Proteolytic systems that operate in atrophic muscles progressively reduce the muscle protein content and so the sarcolemma, ECC and the force generation. In this review we will focus on the more relevant changes of the sarcolemma, excitation-contraction coupling, ECC and mechano-transduction evaluated by electrophysiological methods and observed from early- to long-term denervated skeletal muscles. This review put in particular evidence that long-term denervated muscle maintain a sub-population of fibers with ECC and contractile machinery able to be activated, albeit in lesser amounts, by electrical and mechanical stimulation. Accordingly, this provides a potential molecular explanation of the muscle recovery that occurs in response to rehabilitation strategy as transcutaneous electrical stimulation and passive stretching of denervated muscles, which wre developed as a result of empirical clinical observations.
\end{abstract}

Key Words: Excitation-contraction coupling; L-type $\mathrm{Ca}^{2+}$ current; Mechano-transduction; Skeletal muscle; Long-term denervation

European Journal Translational Myology - Myology Reviews 2010; 1 (3): 121-130

1. Skeletal muscle fiber type plasticity

2. Proteolytic systems in atrophic muscles

3. The balance of the muscular functions depends on extra-muscular and muscular signals

4. $\mathrm{Ca}^{2+}$-dependent and independent muscular intracellular signals

5. Mechano-sensitivity, mechano-trasduction and cytoskeleton-nucleus pathways

6. Excitation-contraction coupling in normal skeletal muscles

7. Reciprocal interaction between L-CaC and RYR1/CRC

8. Excitation-contraction coupling in rat denervated skeletal muscles

9. Conclusion
Skeletal muscle atrophy can be defined as a wasting or decrease in muscle mass and muscle force generation owing lack of use, ageing, injury, or disease. Thus, the etiology of atrophy can be different. Atrophy resulting from disuse (muscle unloading, immobilization, bed rest, and spaceflight) and described as acute atrophy, is readily reversible by exercise and is the consequence of the lack of muscle activity that reduced the gene activation and protein synthesis. The age-related loss of muscle mass and strength, sarcopenia, may be considered to be chronic. Muscle atrophy resulting from chronic disease rather than disuse is described as cachexia and generally arises either from permanent damage of motoneurons or from muscle diseases. Both causes can be the result of either genetic abnormality of nerves or muscles, or systemic diseases. In motoneuron pathology muscle 


\section{Excitation-contraction coupling in denervated muscle}

European Journal Translational Myology - Myology Reviews 1 (3): 121-130, 2010

atrophy is the consequences of affected signal from nerves (action potential rate, neurotransmitter release). Muscle pathology involves genetic abnormality with lack or affected myofibrillar contractile or cytoskeleton proteins. Atrophy in denervated muscle is a consequence of two factors: 1) the complete lack of motoneuron activity inducing the deficiency of neurotransmitter release and 2) the muscles disuse. In accord, a severe atrophy and degeneration of leg muscles tissue does not occur in patients with upper motor neuron lesions even 20 years after thoracic-level spinal cord injury, SCI [38]. In such SCI the lower motoneuron (LMNs) activity is reduced but it is still present, in a certain degree. In contrast, atrophy of leg muscles is particularly severe when the injury destroys the LMNs and, therefore, the contacts between neurons and muscle. During the first days after LMNs SCI, human muscles become less excitable by transcutaneous electrical stimulation (functional electrical stimulation, FES) because the nerve degenerates and so FES can not act by activating the motoneurons. Instead, FES can only operate by direct activation of the less excitable muscle fibres so that, after nerve injury the chronaxie becomes longer, being that of the denervated skeletal muscle [7,28]. The progress of muscle atrophy in denervated muscle is time dependent. In mammals changes of the passive electrical properties of the sarcolemma [15], in transverse tubules organization [68], sarcolemmal $\mathrm{Ca}^{2+}$ current, and the ability to sustain tension during prolonged contractions [19] were just observed in the first weeks after muscle denervation. Muscle atrophy advances faster in the early weeks after denervation but then progresses slower and it may reach a steady-state that is maintained for long time $[2,62]$. Within months after complete injury of the conus medullaris and cauda equina, the muscles are no longer excitable by commercially available electrical stimulators. This is because they have undergone severe disorganization of the sarcolemmal proteins, excitation-contraction coupling (ECC) apparatus, cytoskeleton, metabolic activity and contractile elements (i.e. myofibrils). Finally, after several years of LMN denervation, muscle fibers are almost completely replaced by adipose and fibrous tissues [37,52], therefore muscle degeneration superimposes to muscle atrophy. We have to take into account that many aspects of the early responses to denervation of limb skeletal muscles are similar in all mammalian species investigated in detail. If, however, later stages of denervation are examined there are indications (although no hard evidence) of differences between muscles and species particularly in the time course of the atrophy (i.e. alteration after a few months in rat can be observed up to one year in humans) [2,6,52]. Skeletal muscle atrophy involves many protein systems; in this review we will focus on the more relevant changes of the excitation-contraction coupling, ECC, and mechano-transduction observed in early- and long-term denervated skeletal muscles.

\section{Skeletal muscle fiber type plasticity}

Skeletal muscles functions are plastic, that is depending on their activity they can reversibly change from normal to hypertrophic and atrophic state. The maintenance of skeletal muscle depends upon the imbalance between these two states. Atrophic conditions share the commonality of an imbalance resulting in reduced protein synthesis and increased protein breakdown/proteolysis, which in turn results in reduced muscle mass and muscle fiber size. The imbalance involves the gene activation and, as a consequence, the whole synthesis of proteins of sarcolemma, sarcoplasmic reticulum, extra- and myofibrillar-cytoskeleton, sarcomeric and of the mitochondria.

Mammalian skeletal muscles express particular isoforms of myosin heavy chain $(\mathrm{MyHC})$ and are classified as slow (type I) and fast (type II) fibers; the latter can be further subdivided into three subsets: type IIA, IIX and IIB. These fibers also differ in oxidative enzyme and mitochondrial content, which is higher in type I and IIA (fast oxidative) fibers than in type IIX (fast intermediate) and IIB (fast glycolytic) fibers. Velocity of contraction is associated with the type of MyHC isoforms, whereas resistance to fatigue is related to oxidative enzyme expressed. In accord, type I fibers show low velocity of shortening and high resistance to fatigue, and type IIB fibers show high velocity of shortening and low resistance to fatigue. Fiber type composition can be modulated by nerve activity. For example, muscle inactivity tends to shift $\mathrm{MyHC}$ expression and fiber type properties, following the compulsory pathway $\mathrm{I} \rightarrow \mathrm{IIA} \rightarrow \mathrm{IIX} \rightarrow \mathrm{IIB}$, whereas increased activity and functional overload promote a change in the opposite direction: IIB $\rightarrow$ IIX $\rightarrow$ IIA $\rightarrow$ I $[12,57]$. So, atrophy of denervated muscles can be reduced by increasing their activity as by passive movements or FES. However, the above shift of MyHC expression may be different in slow respect to fast muscle and the adaptive changes subsequent to unloading may be more dependent on the muscle function (involving mainly postural muscles) than on the fiber type $[12,14,49]$.

\section{Proteolytic systems in atrophic muscles}

The skeletal muscle protein loss in atrophic muscle involves three major proteolytic systems [34]: one calcium dependent (the cytosolic calcium-dependent calpain system) $[33,53]$ and two calcium independent (the lysosomal proteases, i.e., cathepsins, and the ATPdependent ubiquitin-proteasome system). [42].

Factors such as TNF- $\alpha$, IL-1 and IL 6, glucocorticoids, myostatin, and reactive oxygen species can induce muscle protein loss under specified conditions. The different etiology of muscle atrophy is put in evidence 


\section{Excitation-contraction coupling in denervated muscle}

European Journal Translational Myology - Myology Reviews 1 (3): 121-130, 2010

by the diverse involvement of these factors in the genesis of atrophy. Unloading-induced atrophy does not require myostatin. Thus, whereas myostatin may contribute to atrophy in cachexia it is not required for disuse atrophy. Treatment of unloaded rats with an inhibitor of glucocorticoids, RU-38486, also did not inhibit disuse atrophy. Thus glucocorticoids do not appear to be required for disuse atrophy whereas in the case of cachexia, glucocorticoids seem to be a contributing factor to muscle wasting. There is no evidence that TNF- $\alpha$ or other cytokines are involved in disuse atrophy no difference was found in TNF- $\alpha$ protein levels in unloaded muscle. However, in cachexia TNF- $\alpha$ and other cytokines such as IL- 1 and IL- 6 are increased and administration of TNF- $\alpha$ can induce cachexia [43]. Thus, with cachexia, but not with disuse, cytokines are key triggers of muscle wasting. Finally, the NF- $\alpha$ transcription factor complex has been implicated in muscle atrophy attributable to both disuse and cachexia, but the specific family members involved in the two types of atrophy are distinct [34,39]. These are important findings that show differences in the molecular signaling for different types of muscle and, therefore, that there may be more specific molecules to target in the development of therapies related to denervated muscle wasting.

Another recent work has shown a role for calpains in muscle atrophy resulting from sepsis. Sepsis induced by cecal puncture leads to Z-band disintegration, increased release of myofilaments, and increased mRNA of calpain 1, calpain 2, and calpain 3 in extensor digitorum longus muscle [70]. However, treatments of rats with dantrolene (an inhibitor of $\mathrm{q} \gamma$, $\mathrm{L}-\mathrm{CaC}$ and $\mathrm{RYR} 1 / \mathrm{CRC}$ and, in turn, of ECC; see below) attenuate these changes by inhibiting the release of calcium from the sarcoplasmic reticulum. The caspases, proteins involved in apoptosis that have specific proteolytic activity, were recently shown to have a role in disease-related muscle atrophy $[10,18]$. The caspases have been proposed to have a role in the initial step in myofibrillar proteolysis by cleavage of actomyosin. In this way, the caspases may be similar to the calpains in making myofibrillar proteins available for ubiquitination.

Denervation of muscle (often with associated aberrant reinnervation) is regarded as a potent trigger to sarcopenia, both associated with ageing and neuromuscular disorders [59], and it has recently been examined at the molecular level [50]. The use of IGF-I electroporation, recombinant human IGF-I and the peptide representing mechano-growth factor (MGF) have all been considered for ameliorating such neuromuscular conditions, including muscular dystrophy and motor neuron disease [41].
3. The balance of the muscular functions depends on extra-muscular and muscular signals

The balance between hypertrophy and atrophy is regulated by extra-muscular and muscular signals.

The first extra-muscular signal is the motoneurones activity others are hormonal as catecholamines, insulin, thyroid hormones, sex hormones, glucocorticoids. Various growth factors stimulate satellite cell proliferation during muscle hypertrophy and regeneration $[22,32]$.

Skeletal muscle itself is a major contributor to a variety of metabolic conditions since autocrine-paracrine loops involving growth factors released by the muscle fibers themselves are implicated in activity-dependent muscle fiber atrophy-hypertrophy balancing. For example, insulin-like growth factor 1 (IGF-1) splicing variants produced by muscle cells are upregulated during muscle hypertrophy induced by overload, stretch or stretch combined with electrical stimulation. Another autocrine-paracrine growth factor is sphingosine 1-phosphate, S1P $\quad[11,16,23,24,70]$. Finally, there are locally generated negative regulators of muscle functions as IL-1, IL-6 and TNF- $\alpha$.

\section{4. $\mathrm{Ca}^{2+}$-dependent and independent muscular intracellular signals}

We have to take into consideration the role of calcium handling that is concerned in many $\mathrm{Ca}^{2+}$-dependent processes as troponin $\mathrm{C}$, TnC, involved in the crossbridge activation and force generation; calmodulin involved in $\mathrm{L}-\mathrm{CaC}$ inactivation. The intracellular $\left[\mathrm{Ca}^{2+}\right]$ results from ryanodine receptors (RyRs) opening, $\mathrm{Na}^{+} / \mathrm{Ca}^{2+}$ excengers and $\mathrm{Ca}^{2+}$-pumps expressed in sarcolemmal and sarcoplasmic reticulum membrane $[8,12,13]$.

Calcium-dependent calpain system involved in calpain substrates are proteins that are involved in the assembly and scaffolding of myofibrillar proteins such as titin, vinculin, C-protein, nebulin, and others. Finally, the intra-sarcomeric cytoskeleton protein Titin is a $\mathrm{Ca}^{2+}$-dependent protein capable of producing a passive tension during sarcomere contraction [36]. It is, in fact, a large elastic proteins linking the thick filaments to the Z-disc, so that the sliding of myosin filaments induces changes in the elastic domain of the protein.

Other $\mathrm{Ca}^{2+}$-dependent proteins are involved in paths activating the gene expression as the $\mathrm{Ca}^{2+}$-calmodulin dependent Calcineurin [40,56]. Calcium/calmodulindependent protein kinase IV (CaMKIV) has been identified as a major regulator of mitochondrial activity [50].

\section{Mechano-sensitivity, mechano-transduction and cytoskeleton-nucleus pathways}

Many evidences suggest a significant role of physical forces as passive stretching or active contraction in exercise, in the development and maintenance of 


\section{Excitation-contraction coupling in denervated muscle}

European Journal Translational Myology - Myology Reviews 1 (3): 121-130, 2010

skeletal muscle mass and in the onset and maintenance of several muscle disorders [1,16,54]. About the mechanisms by which mechanical stress modulates muscle physiology and pathophysiology there is a growing list of signaling pathways that are activated in response to mechanical stimulation in skeletal muscle cells. These include the $\mathrm{Ca}^{2+}$-independent and $\mathrm{Ca}^{2+}$ dependent signaling molecules [24,30] and the cytoskeleton [35]. Sarcomeres are connected to the sarcolemma by extrasarcomeric cytoskeletal proteins forming a morphological and functional unit. Among the extrasarcomeric proteins, desmin [47] links the sarcolemma to the sarcomeres at Z-disk and the costameric proteins such as vinculin, spectrin, talin, distrophin $[20,21,46]$, which, being localized in rib-like bands beneath the sarcolemma, connect the cytoskeleton to the cell surface. Interestingly, Desmin also links to the nuclear envelop, so it is a path that connect the sarcolemma to nucleus and is involved in mechano-trasduction regulating the gene activation $[65,67]$. This mechanical path parallels other signals (described above) acting directly on the nucleus and involving $\mathrm{Ca}^{2+}$-activated molecules, such as the $\mathrm{Ca}^{2+}$ calmodulin-dependent calcineurin $[9,40,56]$.

Mechanical signaling path to the nucleus involves the integrity of the sarcoglican-anchoring protein-actin cytoskeleton [29,30,35]. The mechanical tension of actin filaments is regulated by a $\mathrm{Ca}^{2+}$-independent $\mathrm{Rho}$ path and by its contraction via the $\mathrm{Ca}^{2+}$-dependent activation of the non sarcomeric myosin II $[23,24]$. In myoblasts and myotubes mostly $\mathrm{Ca}^{2+}$ entry in the sarcoplasma depends on the activity of stretchactivated-Ca ${ }^{2+}$ channels (SACs) of the sarcolemmal membrane [23]. These are cationic channels whose activation determines an influx of $\mathrm{Na}^{+}$and $\mathrm{Ca}^{2+}$ ions that, in turn, causes intracellular $\mathrm{Ca}^{2+}$ increase and the fiber depolarization. In adult, differentiated skeletal muscle fibers the most important $\mathrm{Ca}^{2+}$ signal for sarcomeric contraction came from ECC. The intracellular $\left[\mathrm{Ca}^{2+}\right]$ increase is important as a signal to the nucleus about the entity and type of muscle contraction.

Disturbed intracellular $\mathrm{Ca}^{2+}$ signaling is involved in muscle atrophy. The altered $\mathrm{Ca}^{2+}$ homeostasis is related to a leaky plasma-membrane and loss of its mechanical properties causing fragility and less stifness, depending on the anomalous cytoskeleton organization [2,8,13]. This in turn affects not only the properties of plasmamembrane ionic channels but also the gene expression. The result is an increase of the SAC and a decrease of the L-CaC expression. Moreover, L-CaC become mechano-sensitive being more activated by stretch. In other words denervated fibers regress and express SACs and L-CaC as in myoblasts/myotubes.

\section{Excitation-contraction coupling in normal skeletal muscles}

In skeletal muscle fibres the generation of the action potential in the sarcolemma causes the excitationcontraction coupling (ECC) by triggering a series of events that ends with the contraction of the fibre $[51,58]$. Action potential propagates into the fiber via the $\mathrm{T}$ tubular system, TT, where the dihydropyridine receptors (DHPR) lie arranged in tetrads. Each unit of the tetrad is also a voltage operated L-type $\mathrm{Ca}^{2+}$ channel (L-CaC), consisting of five subunits: $\alpha 1, \alpha 2, \beta$, $\gamma$ and $\delta$. The pore-forming unit $\alpha 1$ has an amino acidic sequence organized in four repeated domains (I, II, III, IV), each containing six transmembrane segments (S1S6). The S4 segments contain positively charged amino acid residues. When the TT is depolarized by the action potential the charged S4-segment senses the new potential and moves.

This movement, recorded by electrophysiological techniques, is called intramembrane charge movement (ICM). ICM determines the movement of the loop between the II and III domain. Consequently, the coupled ryanodine receptor type $1 / \mathrm{Ca}^{2+}$-release channel (RyR1/CRC) of the sarcoplasmic reticulum (SR) opens and the luminal $\mathrm{Ca}^{2+}$, stored in the $\mathrm{SR}$, can flow into the myoplasm. The $\mathrm{Ca}^{2+}$ released by RyR1/CRC opens the uncoupled $\mathrm{Ca}^{2+}$-dependent RyRs, type 2 and $3 / \mathrm{CRCs}$ via $\mathrm{Ca}^{2+}$-induced $\mathrm{Ca}^{2+}$ release mechanism determining a further $\mathrm{Ca}^{2+}$ release. The total $\mathrm{Ca}^{2+}$ released reached the $\left[\mathrm{Ca}^{2+}\right] \mathrm{i}$ able to activate the actomyosin coupling and so the cross-bridge contraction.

ICM involves three groups of charges with different voltage thresholds, voltage dependence and function. In fact, in normally polarized skeletal muscle fibers, ICM has been resolved into three components, an early $\mathrm{q} ß$, evoked by any depolarizing step, and two delayed components, q $\gamma$ and qh [11,21] evoked only by voltage steps more positive than a certain threshold (about -56 and $-38 \mathrm{mV}$ in frog and rat, respectively). The time course of $\mathrm{q} ß$ shows a monotonic decay and it seems not to be involved in ECC since the total amount of charge moved is not affected by pharmacological interventions directed at $\mathrm{L}-\mathrm{CaC}$ such as $\mathrm{Cd}^{2+}$, nifedipine or alkanols. The hump-form charges $\mathrm{q} \gamma$ and qh can be resolved into two different ICM components by evaluating the voltage dependence of the amount of charge moved by depolarizing steps above the voltage threshold. In particular, the $q \gamma$ movement triggers the opening of the coupled RyRs/CRCs, allowing a high $\mathrm{Ca}^{2+}$ flux from the $\mathrm{SR}$ into the myoplasm and promoting muscle contraction. The qh charge mobilization move slower than $\mathrm{q} \gamma$ and determines the opening of the sarcolemmal L-CaC that allows $\mathrm{Ca}^{2+}$ influx $\left(\mathrm{I}_{\mathrm{Ca}}\right)$ from the external medium into the myoplasm. This may further enhance ECC by acting on RyRs/CRCs via $\mathrm{Ca}^{2+}$-induced $\mathrm{Ca}^{2+}$ release. So, $\mathrm{DHPR} / \mathrm{L}-\mathrm{CaC}$ has a dual function being a voltage 


\section{Excitation-contraction coupling in denervated muscle}

European Journal Translational Myology - Myology Reviews 1 (3): 121-130, 2010

sensor for RYR1/CRC activation and a functional Ltype $\mathrm{Ca}^{2+}$ channel.

What is the physiological significance of the skeletal muscle L-type $\mathrm{Ca}^{2+}$ current? Single contractions of skeletal muscle fibers do not require $\mathrm{Ca}^{2+}$ current through L-CaC because in skeletal muscle-type EC coupling the mechanical interaction between the voltage sensor for EC coupling (i.e., L-CaC) and the $\mathrm{RYRs} / \mathrm{CRCs}$ determines a high $\mathrm{Ca}^{2+}$ release channels from the SR. Thus, skeletal muscle fibers produce normal twitches in the temporary absence of external $\mathrm{Ca}^{2+}[66]$. In contrast, during tetanic contractions, $\mathrm{I}_{\mathrm{Ca}}$ is involved in maintaining force. In accord, since normal daily activities require sustained activation of skeletal muscles, $\mathrm{Ca}^{2+}$ influx through $\mathrm{L}-\mathrm{CaC}$ should play an important role. $\mathrm{Ca}^{2+}$ entry can enhance contraction directly, or entering $\mathrm{Ca}^{2+}$ may be sequestered into the SR and thereby increase the amount of $\mathrm{Ca}^{2+}$ available for release in response to subsequent action potentials, which would lead to an increase in contractile force. Distinct kinetic models are required to account for L$\mathrm{CaC}$ channel activation in frog [26] and mammalian muscle $[11,45]$. However, in all the models the charge particles involved in the opening of $\mathrm{L}-\mathrm{CaC}$ move coordinately because of the interaction between them. All the models involved various steps, slow and fast, activated at different voltage threshold. The consequence is that a depolarization state of the fibers determines a faster opening of $\mathrm{L}-\mathrm{CaC}$.

Finally, also the inactivation of $\mathrm{L}-\mathrm{CaC}$ is accomplished by various steps and is regulated by at least three mechanisms that concur to reduce the $\mathrm{Ca}^{2+}$ entry: 1) $\mathrm{Ca}^{2+}$ depletion of the TT system that is regulated by the TT volume; 2) voltage-dependent [27] and 3) $\mathrm{Ca}^{2+}$ dependent inactivation. This latter is modulated by $\mathrm{Ca}^{2+}$-calmodulin [66]. This L-CaC inactivation mechanisms may be important for fine-tuning regulation of intracellular $\left[\mathrm{Ca}^{2+}\right]$ and consequently of skeletal muscle function.

\section{Reciprocal interaction between $L-C a C$ and RYR1/CRC}

The ECC is a simple one-way interaction between two proteins that is the voltage-sensing promotes the

RyR/CRC activation via mechanical and $\mathrm{Ca}^{2+}$ dependent coupling. The idea to be considered is that manipulations of the RyR should reciprocally influence the behavior of any charge components with which it makes allosteric contact [4] and should spare only charge components that are not supposed to originate in the $\mathrm{L}-\mathrm{CaC}$ and/or that are scarcely involved in ECC. Indeed, experimental results suggests a more complex functional communication. A reciprocal interaction, or cross-talk, is possible between these two proteins. Thus, in addition to 'receiving' the orthograde ECC signal from the L-CaC, RyR/CRC 'answer' with a retrograde regulation that facilitate the movement of the $\mathrm{q} \gamma$ and $\mathrm{qh}$ charges and increases the $\mathrm{Ca}^{2+}$ channel activity of the L-CaC [44] causing an enhancement of $\mathrm{I}_{\mathrm{Ca}}$. Nifedipine reduced the amount of $\mathrm{q} \gamma$ and qh moved by $\sim 90 \%$ and $\sim 55 \%$ respectively, whereas 1-alkanols completely abolished them. Ryanodine and Ruthenim Red did not affect the amount of q $\gamma$ and qh moved, but shifted their voltage dependence and that of $\mathrm{I}_{\mathrm{Ca}}$ activation more positively by $\sim 4-9 \mathrm{mV}$. Conversely, 1 alkanols, Ryanodine and RR spared $q \beta$. The effect of ryanodine together with those of nifedipine and 1alkanols, are a further demonstration that $\mathrm{q} \gamma$ and $\mathrm{qh}$ both reside in the DHPR/L-CaC and represent separate independent processes from $\mathrm{q} \beta$. Moreover, these results demonstrate that, in the absence of RyR/CRC blockers, the opening of the RyR/CRC facilitates $\mathrm{q} \gamma$ and qh movement as well as the opening of $\mathrm{L}-\mathrm{CaC}$ by a retrograde signal and, in turn, the ECC process [60,61]. Conversely, it may be supposed that any reduction of RyR1/CRC functionality or expression could affect the ECC.

Again, increases the number of uncoupled RYR/CRC supporting the concept that DHPR-RYR1 uncoupling results in alterations in the voltage-gated sarcoplasmic reticulum $\mathrm{Ca}^{2+}$ release mechanism, decreases in myoplasmic $\mathrm{Ca}^{2+}$ elevation in response to sarcolemmal depolarization, reduced $\mathrm{Ca}^{2+}$ supply to contractile proteins and reduced the force of contraction with aging $[48,69]$.

\section{Excitation-contraction coupling in rat denervated skeletal muscles}

Denervated rat leg muscles (soleus, tibialis anterior, gastrocnemius, EDL) showed a progressive decrease in muscle weight-to-body weight ratio. This decrease was very marked in the first 3 weeks, progressed slower up to 26 weeks whereas later the decrease progressed quite slowly indicating that the late loss of muscle mass is negligible [3,62].

The muscle weight-to-body weight ratio changes are paralleled by alterations involving a progressive reduction of i) fiber diameter, iii) T-tubule surface area, iv) membrane resistance and resting membrane potential, v) expression and functionality of voltagedependent $\mathrm{Na}^{+}$channels, index of a less muscle excitability, vi) expression and voltage dependence of L-CaC, index of an affected ECC apparatus, vi) loss of the sarcomeric structure and reduced contractility. Because of this similar time dependence of all the above parameters it is hard to evaluate the trigger signal of atrophy.

Notably, in long-term denervation despite the loss of the sarcomeric machinery denervated muscles maintain some fibers able to activate the altered ECC process and to generate force, albeit in lesser amounts. The reduced values of resting membrane resistance and the depolarized resting membrane potential in denervated fibers suggest a leaky sarcolemma [55] and an increase of intracellular $\mathrm{Ca}^{2+}$ concentration; this is confirmed by the shift in reversal potential of the $\mathrm{L}-\mathrm{CaC}$ current 


\section{Excitation-contraction coupling in denervated muscle}

European Journal Translational Myology - Myology Reviews 1 (3): 121-130, 2010

toward a more negative potential. This may be a starting mechanism that reduces membrane excitability and the efficacy of electrical stimulation in short-term and, to a greater degree, in long-term-denervated muscles.

The reduced fiber diameter and the depolarized state of the denervated rat fiber are in agreement with the reduced action potential conduction velocity observed in long-term-denervated human muscles. In denervated muscle the voltage-dependence for $\mathrm{I}_{\mathrm{Ca}}$ activation is shifted towards more positive potentials and consequently stronger depolarization mast be applied to activate $\mathrm{L}-\mathrm{CaC}$. These findings are in agreement with the reduced excitability found in muscle of SCI patients as increased values of chronaxie.

The reduced T-tubule surface area is an index of a reduced T-tubule volume. So, the total T-tubule $\mathrm{Ca}^{2+}$ content could be reduced and this could be a factor that enhances the $\mathrm{L}-\mathrm{CaC}$ inactivation due to T-tubule $\mathrm{Ca}^{2+}$ depletion. Moreover, the increased number of RyR1 uncoupled with L-CaC may be another factor of the altered ECC since the reduced potentiating action of the retrograde action of $\mathrm{RyR} 1$ on $\mathrm{L}-\mathrm{CaC}[4,60,61]$. However, the presence of residual functional voltagedependent $\mathrm{Na}^{+}$and L-type $\mathrm{Ca}^{2+}$ channels may allow FES to activate $\mathrm{Na}^{+}$and $\mathrm{L}-\mathrm{CaC}$ and in turn the affected EC coupling process. The resulting transient increase of intracellular $\left[\mathrm{Ca}^{2+}\right]$ may be the trigger event that activates $\mathrm{Ca}^{2+}$-dependent signaling pathways to the nucleus, thus inducing the expression of musclespecific proteins in the sarcoplasma and sarcolemma improving the EC coupling process, rebuilt the sarcomeric structure, the muscle mass and restoring the contractile machinery.

Moreover, in denervated muscle fibers the expression of stretch activated channels (SACs) increases [64] and the $\mathrm{L}-\mathrm{CaC}$ are more sensitive to stretch [63]. Thus, due to this increased mechano-sensitivity, passive stretching of denevated muscles may ameliorate the $\mathrm{Ca}^{2+}$ entry from the external medium [17]. Denervated skeletal muscle appears as stabilized in a less differentiated state for its increased SAC expression and sensibility resembling myoblast-myotube. Finally, from these results we may suppose that the effects of FES could be improved in stretched muscles respect to muscles at resting length. The leaky sarcolemma may be an index of the affected structure of the extra- and intra-myofibrillar myofibrillar cytoskeleton that decreases the transport of new proteins toward the sarcolemma and the sarcolemmal stiffness [55].

\section{Conclusion}

Permanently denervated muscles undergo 3 stages of alteration. An early phase with a rapid atrophy. The following medium phase is a period of slow progressive atrophy and the last phase (long term denervated muscle) the fiber sizes and ECC function of the severely atrophic muscle fibers remain stable $[2,3$,
62]. Meanwhile, myofibers decrease in number and fibrosis increases, the residual surviving fibers conserve some functionality as excitability and ECC function with an increased mechano-sensitivity. Moreover, despite the disassembled sarcomeric apparatus, fibers are able to maintain residual contractile activity.

Altogether, these findings support the hypothesis that electrical stimulation-induced changes in intracellular $\left[\mathrm{Ca}^{2+}\right]$ may mimic the lost nerve influence and may play a key role in modifying denervated muscle gene expression. Hence, these observations provide a potential molecular explanation of the muscle recovery that occurs in response to the rehabilitation strategy of FES in mammals and humans [3,5,38], which was developed as a result of empirical clinical observations $[37,38]$. In SCI patients after months of twitch training [37], and thus of intracellular $\left[\mathrm{Ca}^{2+}\right]$ transients, the restored muscle morphology and tetanic contractility agree with improvements of the synthesis/degradation balance of sarcolemmal, ECC, cytoskeleton and myofibrillar proteins. The increased mechanosensitivity of denervated muscle agrees with the recovery effects of passive stretch [31].

\section{List of non-standard abbreviations:}

CRC: $\mathrm{Ca}^{2+}$ release channel; CaMKIV: calcium/calmodulin-dependent protein kinase IV; DHPR: dihydropyridine receptor; ECC: excitationcontraction coupling; FES: functional electrical stimulation; $\mathrm{I}_{\mathrm{Ca}}$ : L-type $\mathrm{Ca}^{2+}$ current; IGF-1: insulinlike growth factor 1; IL-1 and IL-6: interleukin 1 and 6; L-CaC: L-type $\mathrm{Ca}^{2+}$ channel; LMN: lower motoneuron; MGF: mechano-growth factor; MyHC: myosin heavy chain; $\mathrm{NF}-\alpha$ transcription factor complex; RYR: ryanodine receptor; SAC: stretch activated channel; SCI: spinal cord injury; S1P: Sphingosine 1-phosphate; TNF- $\alpha$ : tumour necrosis factor- $\alpha$.

\section{Corresponding Author}

Prof. Fabio Francini, Department of Physiological Sciences, University of Florence, Viale G.B. Morgagni 63, I-50134, Firenze, Italy. Phone: + 0390554237343 Fax: + 0390554379506.

E-mail: fabio.francini@unifi.it

\section{References}

[1] Akimoto T, Pohnert SC, Li P, Zhang M, Gumbs C, Rosenberg PB, Williams RS, Yan Z. Exercise stimulates Pgc-1 transcription in skeletal muscle through activation of the p38 MAPK pathway. J Biol Chem 2005; 280: 19587-19593.

[2] Al-Amood WS, Lewis DM. A comparison of the effects of denervation on the mechanical properties of rat and guinea-pig skeletal muscle $\mathrm{J}$ Physiol (London) 1989; 414: 1-16. 


\section{Excitation-contraction coupling in denervated muscle}

European Journal Translational Myology - Myology Reviews 1 (3): 121-130, 2010

[3] Al-Amood WS, Lewis DM, Schmalbruch H. Effects of chronic electrical stimulation on contractile properties of long-term denervated rat skeletal muscle. J Physiol (London) 1991; 441: 243-256.

[4] Andronachea Z, Hamiltonb SL, Dirksenc RT, Melzera W. A retrograde signal from RyR1 alters DHP receptor inactivation and limits window $\mathrm{Ca}^{2+}$ release in muscle fibers of Y522S RyR1 knock-in mice. Proc Natl Acad Sci U S A. 2009; 106: 4531-4536.

[5] Ashley Z, Salmons S, Boncompagni S, Protasi F, Russold M, Lanmüller H, Mayr W, Sutherland H, Jarvis JC. Effects of chronic electrical stimulation on long-term denervated muscles of the rabbit hind limb. J Muscle Res Cell Motil 2007; 28: 203-217.

[6] Ashley Z, Sutherland H, Lanmüller H, Russold MF, Unger E, Bijak M, Mayr W, Boncompagni S, Protasi F, Salmons S, Jarvis JC. Atrophy, but not necrosis, in rabbit skeletal muscle denervated for periods up to one year. Am J Physiol Cell Physiol 2007; 292: C440-C451.

[7] Ashley Z, Sutherland H, Lanmüller H, Unger E, Li F, Mayr W, Kern H, Jarvis JC, Salmons S. Determination of the chronaxie and rheobase of denervated limb muscles in conscious rabbits. Artificial organs 2005; 29(3): 212-215.

[8] Barritt GJ. Receptor-activated $\mathrm{Ca}^{2+}$ inflow in animal cells: a variety of pathways tailored to meet different intracellular $\mathrm{Ca}^{2+}$ signalling requirements. Biochem J 1999; 337: 153-169.

[9] Bassel-Duby R, Olson EN. Signaling pathways in skeletal muscle remodeling. Annu Rev Biochem. 2006; 75:19-37.

[10] Belizario JE, Lorite MJ, Tisdale MJ. Cleavage of caspases-1, $-3,-6,-8$ and -9 substrates by proteases in skeletal muscles from mice undergoing cancer cachexia. Br J Cancer 2001; 84: 1135-1140.

[11] Bencini C, Squecco R, Piperio C, Formigli L, Meacci E, Nosi D, Tiribilli B, Vassalli M, Quercioli F, Bruni P, Zecchi S, Francini F. Effects of Sphingosine 1-phosphate on excitationcontraction coupling in mammalian skeletal muscle. J Mus Res Cell Mot 2003; 24: 539-554.

[12] Berchtold MM., Brikmeier H, Muntener M: Calcium ion in skeletal muscle: its role for muscle function, plasticity, and disease. Physiol Rev 2000; 80: 1215-1265.

[13] Berridge M J, Lipp M, Bootman D. The versatility and universality of calcium signalling. Nature Rev Mol Cell Biol 2000; 1:11-21.

[14] Dedkov EI, Borisov AB, Carlson BM. Dynamics of postdenervation atrophy of young and old skeletal muscles: differential responses of fiber types and muscle types. J Gerontol A Biol Sci Med Sci 2003; 58:984-91.

[15] Delbono O. Calcium current activation and charge movement in denervated mammalian skeletal muscle fibers. J Physiol (London) 1992; 451: 187-2003.

[16] Dogra C, Changotra H, Jon E. Wergedal JE, Kumar A. Regulation of phosphatidylinositol 3kinase $(\mathrm{PI} 3 \mathrm{~K}) / \mathrm{Akt}$ and nuclear factor-kappa $\mathrm{B}$ signaling pathways in dystrophin-deficient skeletal muscle in response to mechanical stretch. J Cell Physiol 2006; 208: 575-585.

[17] Dow DE, Cederna PS, Hassett CA, Kostrominova TY, Faulkner JA. Number of contractions to maintain mass and force of a denervated rat muscle. Muscle Nerve 2004; 30: 77-86.

[18] Du J, Wang X, Miereles C, Bailey JL, Debigare R, Zheng B, Price SR, Mitch WE. Activation of caspase-3 is an initial step triggering accelerated muscle proteolysis in catabolic conditions. J Clin Invest 2004; 113: 115-123.

[19] Dulhunty AF, Gage PW. Excitation-contraction coupling and charge movement in denervated rat extensor digitorum long and soleus muscle. J Physiol (London) 1985; 358: 75-89.

[20] Ervasti JM, Campbell KP. Dystrophin and the membrane skeleton. Curr Opin Cell Biol 1993; 5: 82-87.

[21] Fabbrizio E, Bonet-Kerrache A, Limas F, Hugon $\mathrm{G}$, Mornet D. Dystrophin, the protein that promotes membrane resistance. Biochen Biophys Res Commun 1995; 213: 295-301.

[22] Favier FB, Henri Benoit H, Freyssenet D. Cellular and molecular events controlling skeletal muscle mass in response to altered use. Pflugers Arch 2008; 456:587-600.

[23] Formigli L, Meacci E, Sassoli C, Chellini F, Giannini R, Quercioli F, Tiribilli B, Squecco R, Bruni P, Francini F, Zecchi-Orlandini S. Sphingosine 1-phosphate induces cytoskeletal reorganization in $\mathrm{C} 2 \mathrm{C} 12$ myoblasts: physiological relevance for stress fibres in the modulation of ion current through stretch-activated channels. J Cell Sciences 2005; 118: 1161-1171.

[24] Formigli L, Meacci E, Vassalli M, Nosi D, Quercioli F, Tiribilli B, Tani A, Squecco R, Francini F, Bruni P, Zecchi Orlandini S. Sphingosine 1-phosphate induces cell contraction via Ca-independent/Rho-dependent pathways in undifferentiated skeletal muscle cells. J Cell Physiol 2004; 198: 1-11.

[25] Francini F, Bencini C, Squecco R, Piperio C. Separation of charge movement components in 


\section{Excitation-contraction coupling in denervated muscle}

European Journal Translational Myology - Myology Reviews 1 (3): 121-130, 2010

mammalian skeletal muscle fibres. J Physiol (London) 2001; 537: 45-56.

[26] Francini F, Bencini C, Squecco R. Activation of L-type calcium channel in twitch skeletal muscle fibres of the frog. J Physiol (London) 1996; 494.1, 121-140.

[27] Francini F, Pizza L, Traina, G. Inactivation of the slow calcium current in twitch skeletal muscle fibres of the frog. J Physiol (London) 1992; 448: 633-653.

[28] Geddes LA. Accuracy limitations of chronaxie values. IEEE Trans Biomed Eng 2004; 51: 176181.

[29] Gerke V, Creutz CE, Moss SE. Annexins: Linking $\mathrm{Ca}^{2+}$ signalling to membrane dynamics. Nat Rev Mol Cell Biol 2005; 6: 449-461.

[30] Glogauer M, Arora P, Yao G, Sokholov I, Ferrier $\mathrm{J}$, McCulloch CA: Calcium ions and tyrosine phosphorylation interact coordinately with actin to regulate cytoprotective responses to stretching J Cell Sci 1997; 110 (Pt 1): 11-21.

[31] Gomes AR, Soares AG, Peviani S, Nascimento RB, Moriscot AS, Salvini TF. The effect of 30 minutes of passive stretch of the rat soleus muscle on the myogenic differentiation, myostatin, and atrogin-1 gene expressions. Arch Phys Med Rehabil 2006; 87(2): 241-246.

[32] Hawke TJ, Garry DJ. Myogenic satellite cells: physiology to molecular biology. J. Appl Physiol 2001; 91: 534-551.

[33] Huang J, Forsberg NE. Role of calpain in skeletal-muscle protein degradation. Proc Natl Acad Sci USA 1998; 95: 12100-12105.

[34] Jackman RW, Kandarian SC. The molecular basis of skeletal muscle atrophy. Am J Physiol Cell Physiol 2004; 287: C834-C843.

[35] Janmey PA. The cytoskeleton and cell signaling: component localization and mechanical coupling. Physiol Rev 1998; 78: 763 - 781.

[36] Kellermayer MSZ, Granzier HL. Calciumdependent inhibition of in vitro thin filament motility by native titin. FEBS Lett 1996; 380: 281-286.

[37] Kern H, Boncompagni S, Rossini K, Mayr W, Fanò G, Zanin ME, Podhorska-Okolow M, Protasi F, Carraro U. Long-term denervation in humans causes degeneration of both contractile and excitation-contraction coupling apparatus that can be reversed by functional electrical stimulation (FES). A role for myofibre regeneration? J Neuropath Exp Neurol 2004; 63: 919-931.

[38] Kern H, Hofer C, Mödlin M, Forstner C, Raschka-Högler D, Mayr W, Stöhr H. Denervated muscles in humans: limitations and problems of currently used functional electrical stimulation training protocols. Artif Organs 2002; 26: 216218.

[39] Lin Y, Brady MJ, Wolanske K, Holbert R, Ruderman NB, Yaney GC. Alterations of nPKC distribution, but normal $\mathrm{Akt} / \mathrm{PKB}$ activation in denervated rat soleus muscle. Am J Physiol Endocrinol Metab 2002; 283(2): E318-325.

[40] Mallinson J, Meissner J, Chang KC. Chapter 2 Calcineurin Signaling and the slow oxidative skeletal muscle fiber type. Int Rev Cell Mol Biol 2009; 277: 67-101.

[41] Matheny RWJr, Nindl BC, Adamo ML. Minireview: Mechano-Growth Factor: A Putative Product of IGF-I Gene Expression Involved in Tissue Repair and Regeneration. Endocrinology 2010; 151: 865-875.

[42] McKinnell IW, Rudnicki MA. Molecular Mechanisms of Muscle Atrophy. Cell 2004; 119 : 907-910.

[43] Moldawer LL, Copeland EM. III. Proinflammatory cytokines, nutritional support, and the cachexia syndrome: interactions and therapeutic options. Cancer 1997; 79: 1828-1839.

[44] Nakai J, Sekiguchi N, Rando TA, Allen PD, Beam KG. Two regions of the Ryanodine receptor involved in coupling with L-Type $\mathrm{Ca}^{2+}$ Channels. J Biol Chem 1998; 273: 13403-13406.

[45] O'Connell KMS, Dirksen RT. Prolonged depolarization promotes fast gating kinetics of Ltype Ca-channels in mouse skeletal myotubes. J Physiol (London) 2000; 529.3: 647-659.

[46] Pardo JV, Siciliano JD, Craig SW. A vinculincontaining cortical lattice in skeletal muscle: transverse lattice elements (costameres) mark sites of attachment between myofibrils and sarcolemma. Proc Natl Acad Sci 1983; 80: 10081012.

[47] Paulin D, Huet A, Khanamyrian L, Xue Z. Desminopathies in muscle disease. J Pathol 2004; 204: 418-427.

[48] Payne AM, Zheng Z, Gonzalez E, Wang ZM, Messi ML, Delbono O. External $\mathrm{Ca}^{2+}$-dependent excitation-contraction coupling in a population of ageing mouse skeletal muscle fibres. J Physiol (London) 2004; 560.1: 137-155.

[49] Raffaello A, Laveder P, Romualdi C, Bean C, Toniolo L, Germinario E, Megighian A, DanieliBetto D, Reggiani C, Lanfranchi G. Denervation in murine fast-twitch muscle: short-term physiological changes and temporal expression profiling. Physiol Genomics 2006; 25: 60-74.

[50] Reznick RM, Shulman GI. The role of AMPactivated protein kinase in mitochondrial 


\section{Excitation-contraction coupling in denervated muscle}

European Journal Translational Myology - Myology Reviews 1 (3): 121-130, 2010

biogenesis. J Physiol (London) 2006; 574.1: 3339.

[51] Rios E, Brum G. Involvement of dihydropyridine receptors in excitation-contraction coupling in skeletal muscle. Nature 1987; 325: 717-720.

[52] Rossini K, Zanin ME, Podhorska-Okolow M, Carraro U. To stage and quantify regenerative myogenesis in human long-term permanent denervated muscle. Basic Appl Myol 2002; 12: 277-286.

[53] Salazar JJ, Michele DE, Brooks SV. Inhibition of calpain prevents muscle weakness and disruption of sarcomere structure during hindlimb suspension. J Appl Physiol. 2010; 108: 120-127.

[54] Sandri M, Lin J, Handschin C, Yang W, Arany ZP, Lecker SH, Goldberg AL, Spiegelman BM. PGC-1alpha protects skeletal muscle from atrophy by suppressing FoxO3 action and atrophy-specific gene transcription. Proc Natl Acad Sci USA 2006; 103(44):16260-16265.

[55] Sbrana F, Sassoli C, Nosi D, Squecco R, Paternostro F, Tiribilli B, Zecchi-Orlandini S, Francini F, Formigli L. Role for stress fiber contraction in surface tension development and stretch-activated channel regulation in $\mathrm{C} 2 \mathrm{C} 12$ myoblasts. Am J Physiol Cell Physiol 2008; 295: C160-C172.

[56] Schiaffino S Serrano AL. Calcineurin signaling and neural control of skeletal muscle fiber type and size. Trends Pharmacol Sci 2002; 23:569575.

[57] Schiaffino S. and Reggiani C. Molecular diversity of myofibrillar proteins: gene regulation and functional significance. Physiol Rev 1996; 76: 371-423.

[58] Schneider MF, Chandler WK. Voltage dependent charge movement of skeletal muscle: a possible step in excitation-contraction coupling. Nature 1973; 242: 244-246.

[59] Solomon AM, Bouloux PMG. Modifying muscle mass - the endocrine perspective. J Endocrinol 2006; 191: 349-360.

[60] Squecco R, Bencini C, Piperio C, Francini F. Ltype $\mathrm{Ca}^{2+}$ channel and ryanodine receptor crosstalk in frog skeletal muscle. J Physiol (London) 2004; 555: 137-152.

[61] Squecco R, Bencini C, Piperio C, Francini F. Reciprocal communication between L-type $\mathrm{Ca}^{2+}$ channel and ryanodine receptor in frog skeletal muscle. Pysiological News 2004; 57: 23-25.
[62] Squecco R, Carraro U, Kern H, Pond A, Adami $\mathrm{N}$, Biral D, Vindigni V, Boncompagni S, Pietrangelo T, Bosco G, Fanò G, Marini M, Abruzzo PM, Germinarlo E, Danieli-Betto D, Protasi F, Francini F, Zampieri S. Despite lost contractility, a sub-population of rat muscle fibers maintains an assessable excitation-contraction coupling mechanism after long-standing denervation. J Neuropathol Exp Neurol. 2009; 68: 1256-1268.

[63] Squecco R, Francini F, Kern H, Biral D, Rossini $\mathrm{K}$, Carraro U. L-type $\mathrm{Ca}^{2+}$ channel mechanosensitivity in long-term denervated Soleus muscle of the rat. Basic Appl Myol 2005; 15:187-190.

[64] Squecco R, Kern H, Biral D, Rossini K, Francini F. (2008) Mechano-sensitivity of normal and long-term denervated Soleus muscle of the rat. Neurol Res 2008; 30 (2): 155-159.

[65] Stein G S, Van Wijnen A J, Stein J L, Lian J B, Pockwinse S H, Mcneil S. Implication for interrelationships between nuclear architecture and control of gene expression under microgravity conditions. FASEB J. 1999; 13S: S157-S166.

[66] Stroffekova K. $\mathrm{Ca}^{2+} / \mathrm{CaM}$-dependent inactivation of the skeletal muscle L-type $\mathrm{Ca}^{2+}$ channel (Cav1.1). Pflugers Arch - Eur J Physiol 2008; 455: 873-884.

[67] Stromer MH. The cytoskeleton in skeletal, cardiac and smooth muscle cells. Histol Histopathol 1998; 13, 283-291.

[68] Takekura H, Tamaki H, Nishizawa T, Kasuga N. Plasticity of the transverse tubules following denervation and subsequent reinnervation in rat slow and fast muscle fibres. J Mus Res Cell Mot 2003; 23: 439-451.

[69] Wang ZM, Messi ML, Delbono O. L-Type $\mathrm{Ca}^{2+}$ channel charge movement and intracellular $\mathrm{Ca}^{2+}$ in skeletal muscle fibers from aging mice. Biophys J 2000; 78: 1947-1954.

[70] Williams AB, Decourten-Myers GM, Fischer JE, Luo G, Sun X, and Hasselgren PO. Sepsis stimulates release of myofilaments in skeletal muscle by a calcium-dependent mechanism. FASEB J 1999; 13: 1435-1443.

[71] Yatomi Y, Ozaki Y, Ohmori T, Igarashi Y. Sphingosine 1-phosphate: synthesis and release. Prostaglandins Other Lipid Mediat 2001; 64: 107122. 